\title{
“DIADORIM SOU EU” E O PROBLEMA BIOGRÁFICO DE GUIMARÃES ROSA ${ }^{1}$
}

\section{“I AM DIADORIM" AND THE BIOGRAPHICAL Problem of Guimarães Rosa}

\author{
Gustavo Castro e Silva ${ }^{2}$ \\ Florence Dravet ${ }^{3}$ \\ Leandro Bessa ${ }^{4}$
}

\begin{abstract}
Resumo: Este artigo tem como objetivo problematizar a expressão "O Diadorim do Grande sertão sou eu”, dita por João Guimarães Rosa (1908-1967) a Afonso Arinos e registrada por Josué Montello, assim como busca circunscrever o problema biográfico do autor mineiro. O texto fundamenta-se na discussão de "crítica biográfica" (SOUZA, 2020) para fazer a leitura do campo biográfico e da personagem Diadorim. A conclusão aponta para a possibilidade de relacionar fato e ficção à pesquisa e à grande carência de estudos biográficos sobre o autor mineiro.

Palavras-chave: Biografia; Guimarães Rosa; Diadorim.
\end{abstract}

Abstract: This article aims to problematize the expression "O Diadorim do Grande sertão sou eu”, spoken by João Guimarães Rosa (1908-1967) to Afonso Arinos and recorded by

\footnotetext{
${ }^{1}$ Texto apoiado pelo Edital DPI/DPG n. 02/2021, da Universidade de Brasília (UnB), de incentivo à execução de projetos de pesquisas científicas, tecnológicas e de inovação com produção de artigo.

${ }^{2}$ Professor do Programa de Pós-Graduação em Comunicação da Universidade de Brasília (UnB): <gustavocastroesilva@gmail.com>.

3 Professora do Mestrado em Comunicação e Economia Criativa e Programa de Pós-Graduação em Educação da Universidade Católica de Brasília (UCB): <flormd@gmail. com>.

${ }_{4}$ Professor do Mestrado em Comunicação e Economia Criativa da Universidade Católica de Brasília (UCB). Doutorando em Comunicação do Programa de Pós-Graduação em Comunicação da Universidade de Brasília (UnB): <lbessa.arte@gmail.com>.
} 
Josué Montello, as well as seeking to circumscribe the biographical problem of the author from Minas Gerais. The text is based on the discussion of "biographical criticism" (SOUZA, 2020) to read the biographical field and the character Diadorim. The conclusion points to the possibility of relating fact and fiction to research and the great lack of biographical studies on the Minas Gerais author.

Keywords: Biography; Guimarães Rosa; Diadorim.

"É impossível separar minha biografia de minha obra" (João Guimarães Rosa)

\section{INTRODUÇÃO}

Passados mais de cinquenta anos da morte de Guimarães Rosa, causa estranheza que nenhum estudo biográfico em profundidade tenha sido produzido sobre o autor mineiro. Em 2008, o goiano Alaor Barbosa publicou pela editora LGE, de Brasília, o livro Sinfonia Minas Gerais: a vida e a literatura de João Guimarães Rosa. Na capa do volume, aparece a indicação "Tomo I", assinalando a intenção do autor em publicar ao menos um segundo volume. Mal saiu o livro, Barbosa e a editora receberam a notícia de que a publicação seria retirada de circulação ${ }^{5}$ e contestada na justiça por Vilma Guimarães Rosa, filha do escritor, que acusava Barbosa de plágio. Os advogados de Vilma alegavam que Barbosa distorcia, mentia e copiava trechos da obra Relembramentos (1983). A ação judicial demorou sete anos para ser decidida, e Vilma, afinal, acabou perdendo a causa, sendo condenada a indenizar financeiramente Barbosa ${ }^{6}$ e a publicizar a decisão judicial nos jornais O Popular (de Goiânia/GO), Folha de S. Paulo (SP) e Correio Braziliense (DF).

No entanto, apesar da reparação financeira, Alaor Barbosa não viria a relançar o livro, nem a publicar o segundo tomo. O livro de Barbosa também seria praticamente esquecido pelos estudiosos da obra rosiana e não receberia recensões críticas, entre outros motivos, pela ausência de sólidas informações biográficas sobre G. Rosa. A polêmica à volta do livro de Alaor Barbosa nos ajudou a perceber o problema da investigação biográfica sobre G. Rosa. E tais problemas não passavam apenas pelas facilidades ou dificuldades impostas pelos familiares do mineiro.

5 Processo disponível em: <https://www.conjur.com.br/20o8-set-2o/justica_proibe_ venda_biografia_guimaraes_rosa>. Acesso em: 24 nov. 2021.

${ }^{6}$ Disponível em: <https://www.dm.jor.br/opiniao/2015/o6/a-vitoria-de-alaor/> e <https:// www.conjur.com.br/2015-jun-o8/filha-guimaraes-rosa-indenizara-autor-biografiaescritor>. Acesso em: 24 nov. 2021. 
Propomos nesteartigo uma aproximação do perfil biográficodeG. Rosa por dois caminhos: primeiro, o documental, a partir dos dados presentes em seu arquivo no Instituto de Estudos Brasileiros, da Universidade de São Paulo (IEB-USP); o segundo, ficcional, ao pretendermos explorar a personagem Diadorim como um duplo do escritor mineiro, a partir de um depoimento que ele mesmo deu a Afonso Arinos de Melo Franco (1905-1990). A revelação biográfica feita por G. Rosa a Afonso Arinos, dias antes da posse na Academia Brasileira de Letras, em 1967, chama a atenção. Ela aparece transcrita nos diários de Josué Montello:

Dias antes da posse, uma noite, [Rosa] foi me visitar. Trazia-me uns dados novos, para ver se eu os queria aproveitar. E de repente, com o dedo em riste diante dos lábios, e depois de olhar em volta, para certificar-se de que estávamos sós, ele fez esta confidência: "O Diadorim do Grande sertão sou eu. Mas isto é só para você” (ARINOS apud MONTELLO, 1998, p. 186).

Nossa pesquisa investigará tal declaração e fará levantamento e checagem de dados do arquivo, com análise e interpretação de documentos primários. Buscamos investigar os arquivos pessoais do escritor, sobretudo aqueles presentes no IEB-USP e na Fundação Casa Rui Barbosa (FCRB), no Rio de Janeiro. Em um primeiro momento, situamos o problema biográfico a partir da noção de "crítica biográfica", especialmente aquela desenvolvida por Eneida Souza (2011; 2020a; 2020b), que propõe a escrita biográfica como um exercício em direção à "máxima invenção" (SOUZA, 2020b, p. 5), à "biografização" ou "biograficidade" (ALHEIT, 2007; 2011; 2019; 2020), ou ainda à "ciência do singular" (DELORY-MOMBERGER, 2015).

Em seguida, trataremos os problemas biográficos específicos ao escritor G. Rosa, tanto os relativos à sua personalidade quanto os de arquivo. Entre outros dados, rastreamos a enigmática afirmação em discussão: "Diadorim [...] sou eu”. Faremos um exercício interpretativo no cruzamento metodológico entre a objetividade dos dados de arquivo, a subjetividade da personalidade do escritor e a inventividade característica da obra. Tal cruzamento requer antes o enfrentamento de alguns aspectos teórico-metodológicos do problema biográfico.

\section{O PROBLEMA BIOGRÁFICO}

As ideias sobre o duplo e a mescla de dados biográficos com dados ficcionais nos ajudam a pensar e a problematizar o próprio gênero 
"biografia”. No campo das Ciências Humanas e Sociais, o gênero ganhou - nas duas últimas décadas - um importante impulso. Alargaram-se os estudos e pesquisas acadêmicos devido às possibilidades de investigação e às dinâmicas referenciais, autorreferenciais e multirreferenciais do campo, assim como devido às múltiplas possibilidades investigativas do ser humano: desde a constituição individual, psíquica, simbólica, passando pela social, política, filosófica, histórica, antropológica, até a educativa e clínica. Vimos surgir em 2008 a Associação Brasileira de Pesquisa (Auto)Biográfica (BIOgraph), ${ }_{7}$ com sua respectiva publicação, a Revista Brasileira de Pesquisa (Auto)Biográfica, ${ }^{8}$ lançada em 2016, e editada pela Universidade do Estado da Bahia (UNEB). A publicação se posiciona em seu "foco e escopo" no "âmbito do movimento biográfico internacional".

Certamente, fazem parte desse "movimento biográfico internacional" (RBPAD, [s.d.], [s.p.]) publicações como a Biography Studies, ${ }^{9}$ surgida em 1985; a Revue Internationale de Recherche Biographique; ${ }^{10}$ o Biography Institute, ${ }^{11}$ surgido em 2004; o Departamento de História e Teoria da Biografia, em 2012, ${ }^{12}$ na Universidade de Groningen, na Holanda; o Collège International de Recherche Biographique en Éducation (Cirbe), em Paris; entre outras iniciativas. No Brasil, além de eventuais dossiês em revistas acadêmicas, ${ }^{13}$ a editora Todavia criou em 2020 o "Prêmio Todavia de NãoFicção", que, segundo a proposta da editora, visa "privilegiar a urgência e

\footnotetext{
7 A BIOgraph tem como objetivos: "1. congregar os profissionais brasileiros que pesquisam (auto)biografias, memória, histórias de vida e práticas de formação; 2. promover e coordenar estudos e pesquisas, eventos e ensino no âmbito da pesquisa (auto)biográfica, memória, histórias de vida e práticas de formação; 3. dialogar com associações congêneres, especialistas nacionais e internacionais e desenvolver ações interdisciplinares no campo de pesquisa-ensino; 4. estimular a divulgação e informação das produções na área de pesquisa (auto)biográfica, memória, histórias de vida e práticas de formação; 5 . promover a crítica e o pluralismo teórico na área em suas diferentes produções e atividades" (RBPAD,

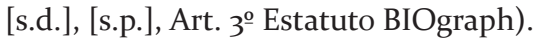

${ }^{8}$ Disponível em: <https://www.revistas.uneb.br/index.php/rbpab>.

${ }_{9}$ Disponível em: <https://www.tandfonline.com/toc/raut2o/current>.

${ }^{10}$ Disponível em: <http://www.lesujetdanslacite.com/1/la_revue_664194.html>.

${ }^{11}$ Disponível em: <https://www.rug.nl/research/biografie-instituut/>.

${ }_{12} \mathrm{O}$ Instituto de Biografia da Universidade de Groningen tem os seguintes objetivos:

1) oferecer uma infraestrutura de apoio e suporte mais específico relacionado a uma variedade de assuntos para estudantes de graduação envolvidos em pesquisas biográficas e 2) estimular o aprofundamento de um referencial teórico sobre a biografia como gênero acadêmico.

${ }^{13}$ Além da Revista Brasileira de Pesquisa (Auto)Biográfica, a Letras de Hoje (PUC/RS) dedicou em abril/junho de 2018 uma edição ao tema.
} 
a pertinência" das biografias em projetos que ampliem "as fronteiras do gênero" (PRÊMIO, [s.d.], [s.p.]).

A expansão editorial de um lado e, de outro, a ampliação das pesquisas no campo das Humanidades deveu-se, entre vários motivos, segundo Eneida Souza (2020), ao "fascínio" que o gênero costuma despertar. Para ela, o potencial criativo e inventivo do gênero junto às possibilidades de aberturas metodológicas e de pesquisas atuam como catalisadores de tal expansão. Não se nega com isso o velho problema epistemológico e metodológico do campo, ou seja, a dificuldade de apreender o jogo entre o vivido e o narrado, ou o problema entre "o ato de viver", "o ato de contar" e o texto que é o produto dessa atividade. Partindo da literatura, Eneida Souza (202ob, p. 1) nomeia de "crítica biográfica" o campo de conhecimento inter ou transdisciplinar capaz de articular tanto a "produção ficcional" como a "documental":

\begin{abstract}
A crítica biográfica, por sua natureza compósita, englobando a relação complexa entre obra e autor, possibilita a interpretação da literatura além de seus limites intrínsecos e exclusivos, por meio da construção de pontes metafóricas entre o fato e a ficção. O fascínio que envolve a invenção de biografias literárias se justifica pela natureza criativa dos procedimentos analíticos, em especial, a articulação entre obra e vida, tornando infinito o exercício ficcional do texto da literatura, graças à abertura de portas que o transcendem. A crítica biográfica, ao escolher tanto a produção ficcional quanto a documental do autor correspondência, depoimentos, ensaios, crítica -, desloca o lugar exclusivo da literatura como corpus de análise e expande o feixe de relações culturais (SOUZA, 202ob, p. 1).
\end{abstract}

Ou seja, para ela, a crítica biográfica "expande o feixe de relações culturais" e tal expansão deve-se à capacidade do gênero de realizar uma dupla e complementar operação, de subjetivação do mundo histórico e social e de socialização da experiência individual: é, ao mesmo tempo e inseparavelmente, o campo de investigação pelo qual os indivíduos se constroem como seres singulares e como seres sociais. Trata-se de um gênero com tendência memorialística (dentro do segmento ensaístico); com tendência artística (no segmento novelístico, de romance-reportagem); eainda com tendência científica (segmento historiográfico). Eneida Souza pensa a crítica biográfica como uma produção criativa em que é necessário um gerenciamento artístico da pesquisa, do texto, da escritura e da própria crítica biográfica. Para alcançar tal objetivo, a autora evoca a possibilidade de criar "pontes metafóricas entre o fato e a ficção" 
(SOUZA, 202ob, p. 1), o que requer "certa flexibilidade ficcional" (SOUZA, 2020a, p. 4):

Conceder ao crítico certa flexibilidade ficcional sobre o objeto em análise, não se prendendo à palavra do autor, mas indo além dela. Por essa razão, o elemento factual da vida/obra do escritor adquire sentido se for transformado e filtrado pelo olhar do crítico, se passar por um processo de desrealização e dessubjetivação (SOUZA, 2020a, p. 4).

Para Eneida Souza, a pesquisa biográfica, longe de se opor ao indivíduo - a subjetividade individual - e à sociedade, como duas entidades separadas que deveriam se enfrentar, concentra-se, ao contrário, em manter juntos os dois termos de uma relação recíproca. Segundo ela, o biográfico não é apenas um espaço de mediação e articulação entre o individual e o social. Deve e pode estar além de um produto ou de uma interação entre a ação dos indivíduos e o determinismo das estruturas, e a maneira pela qual as pessoas se explicam. A crítica biográfica pressupõe um processo de pesquisa engajada no qual estão comprometidos juntamente pesquisadores, pessoas e fatos com os quais se investiga. A autora afirma que o fato biográfico pode passar pela transposição metafórica: "possibilita maior abertura textual” (SOUZA, 2020a, p. 2). E a crítica biográfica deveria abarcar "o mínimo distanciamento e o máximo de invenção" (p. 5):

A crítica biográfica não pretende reduzir a obra à experiência do autor, nem demonstrar ser a ficção produto de sua vivência pessoal e intransferível. As relações teórico-ficcionais entre obra e vida resultam no desejo de melhor entender e demonstrar o nível de leitura do crítico, ao ampliar o polo literário para o biográfico e daí para o alegórico (SOUZA, 2020a, p. 6).

Noutro ponto, ela esclarece:

Essa estratégia referencial às avessas reveste-seainda da antiga poética narrativa, marcada pelo gesto de "mentir-vrai", "mentir-verdadeiramente", operação que reúne princípios enunciativos ligados ao teatro e ao romance, construindo uma cenografia da enunciação. A desestabilização do referencial produz, com efeito, a invenção e a estetização da memória, esta não mais subordinada à prova de veracidade. Trata-se da ação deliberadamente ficcional por parte do sujeito, do gesto de dessubjetivação que o insere no jogo fabular da narrativa (SOUZA, 2020a, p. 7).

Não por acaso "fato e ficção" e "estetização da memória", no "jogo fabular da narrativa”, são aportes teórico-metodológicos da crítica biográfica, mas também estão integrados ao campo das "Histórias de vida”, no campo da Educação e Psicanálise. O papel educativo e clínico da 
biografia é poucas vezes notado e destacado em sua devida importância. Quem chama atenção para tal aspecto presente nas histórias de vida é Peter Alheit (2011; 2019; 2020), Franco Ferrarotti (2007; 2013) e Delory-Momberger (2016). Esses estudiosos falam do efeito terapêutico de coelaboração da experiência a partir do relato. Destacam a importância do encontro, da entrevista face a face, da conversação profunda e focada sobre determinada personagem ou acontecimento. Trata-se daquilo que Eneida Souza chama de "operação que reúne princípios enunciativos ligados ao teatro e ao romance" (2020a, p. 7), algo que Peter Alheit (2011) chama de "biografização" e Delory-Momberger (2016) de "Ciência do singular".

A biografia entendida como "Ciência do singular" coloca o autor do relato em cena. A intenção biográfica desempenha um papel específico na forma como os indivíduos compreendem a si mesmos, aos outros, formam-se e escrevem seus textos. Nessa lógica de subjetivação está a apropriação biográfica, e está também a dimensão socializadora de tal atividade. O método biográfico leva o pesquisador a reconhecer que não sabe ou que só poderá começar a saber (dos arquivos, dos outros e das histórias) com as pessoas mesmas, com o saber das outras pessoas, especialmente com o saber de seus interlocutores, nas tomadas de falas, escutas, conversações, narrativas e releituras.

Peter Alheit (2011, p. 31) define a noção de "biografização" como "capacidade de combinar esses processamentos internos com as condições externas de sociabilidade”. Para ele, biografização é "um código pessoal com o qual nos apoderamos de novas experiências. Cada processo de aprendizagem atual funciona exatamente assim, e por isso toda a aprendizagem é, em certo sentido, “aprendizagem biográfica” (p. 37). Ou ainda: “'código de experiência' particular inequívoco que eles [os autores dos relatos] precisam para incorporar novos conhecimentos para dentro da construção acrescida de experiências e manter sua identidade" (p. 38).

Delory-Momberger (2016, p. 139) segue na mesma linha e, como já dissemos, chama esse processo de "Ciência do singular" ou: "conjunto das operações e dos comportamentos pelos quais os indivíduos trabalham para se dar uma forma própria na qual possam se reconhecer a si mesmos e se fazer reconhecer pelos outros". Outra estudiosa, Maria Teresa del Olmo Ibañez (2015), em sua Teoría de la biografía, dedica um minucioso estudo para entender a formação filosófica e histórica do gênero. Ibañez classifica em dois os tipos de biografias: as diretas (dedutivas) e as indiretas (indutivas), sendo as diretas aquelas em que o autor se apoia em 
fatos, documentos, pesquisas, entrevistas etc., para construir seu relato. No Brasil, poderíamos citar as biografias feitas por Lira Neto e Ruy Castro, por exemplo. No outro tipo, a indireta, o autor parte do fato biográfico para aprofundar uma questão ética, estética, filosófica, teórica, política ou moral, semelhante às biografias escritas por Stefan Zweig (1881-1942) sobre Maria Antonieta (1932), Fernão de Magalhães (1938) ou Honoré de Balzac (1946); e Agostinho da Silva (1906-1994), ao escrever sobre Louis Pasteur (1936) e Moisés (1945).

O que Eneida Souza (202ob, p. 1) propõe, contudo, é um terceiro tipo: o entremeio de biografias diretas e indiretas, justamente por meio do compósito "teoria e ficção" ou "por meio da construção de pontes metafóricas entre o fato e a ficção". A autora coloca a "invenção ou estetização da memória" e o "acontecimento vivido pelo autor ou lembrado, imaginado" (SOUZA, 2020a, p. 5) no centro do debate biográfico. Diz que a crítica biográfica: "não pretende reduzir a obra à experiência do autor, nem demonstrar ser a ficção produto de sua vivência pessoal e intransferível" (p. 5). Nesse sentido, ela se inscreve naquilo que Peter Alheit (2009, p. 79) chamou de "biograficidade", a nossa capacidade de integrar novas experiências narrativas àquelas já vividas ou mesmo a capacidade de produzir e interpretar novas experiências.

Para Ferrarotti (2013, p. 23), o saber biográfico é um conhecimento a dois que se constrói em uma interação intersubjetiva. Seja no campo da educação ou da clínica, a pesquisa biográfica é em essência colaborativa, uma vez que implica ao mesmo tempo um trabalho do sujeito com o qual o pesquisador entra em relação, e o trabalho do pesquisador. Enquanto os sujeitos trabalham para dar sentido às suas experiências, os pesquisadores biográficos trabalham para dar sentido às suas narrativas. Como tal, esse espaço de pesquisa só pode ser um espaço de relacionamento ou, como diz Ferrarotti, de "dinâmica relacional" (p. 23).

Ele faz um apelo para que restauremos à entrevista biográfica toda a sua espessura de interação social. As narrativas biográficas das quais nos servimos não são monólogos face a um observador reduzido ao papel de suporte humano do gravador. Cada entrevista desse tipo é uma interação social complexa, um sistema de papéis, de expectativas, de imposições, de normas e de valores implícitos, frequentemente também de sanções: "a entrevista biográfica nos parece ser um exemplo perfeito do polo clínico das ciências humanas" (FERRAROTTI, 2013, p. 54). 
Se a "fala de si", sob todos os seus registros e em todas as suas diversidades, constitui o material privilegiado de um saber biográfico, ela é também o vetor pelo qual encontramos este "polo clínico" que constitui aos olhos de Franco Ferrarotti a entrevista biográfica. Entendemos por "polo clínico" aqui o espaço de uma relação em que se implementam um cuidado e uma escuta do outro.

Sema pretensão de dar conta dos aspectos conceituais e metodológicos dessa temática, retomemos agora a investigação dos problemas biográficos relacionados à pesquisa sobre $\mathrm{G}$. Rosa.

\section{O PROBLEMA BIOGRÁFICO DE G. ROSA}

No caso de G. Rosa, os problemas biográficos são menos teóricos e mais da ordem da complexidade, ou seja, metodológicos. Sem dúvida, o grande volume de dados de arquivo somado ao pequeno número de pesquisas com interesse biográfico são alguns dos fatores que complicam a elaboração de uma biografia do mineiro. Elencamos alguns dos problemas que retardam temporalmente tal perfil biográfico: 1) dificuldade de sistematização linear e compreensiva do conjunto de mais de nove mil documentos presentes no arquivo do Instituto de Estudos Brasileiros (IEB) da Universidade de São Paulo (USP); 2) dificuldade de sistematização linear e compreensiva do conjunto de quatro mil documentos presentes no arquivo de Aracy Moebius de Carvalho (IEB-USP); 3) diversidade e dispersão de arquivos, distribuídos entre o IEB, a Fundação Casa Rui Barbosa (FCRB), o Acervo de Escritores Mineiros, da Universidade Federal de Minas Gerais (UFMG), os museus Sagarana (em Itaguara - MG), o G. Rosa (Cordisburgo - MG), o Arquivo do Itamaraty, no Rio de Janeiro; 4) a divisão familiar do espólio referente a direitos autorais e bens, dividido entre as família Tess (herdeiros de Aracy Moebius de Carvalho, segunda esposa de G. Rosa) e as filhas Vilma e Agnes (herdeiras de Lygia Cabral Penna), do primeiro casamento do escritor; 5) a quantidade de lugares onde ele morou como diplomata no exterior (Hamburgo, Paris, Bogotá); mais as cidades em que viveu no Brasil (Cordisburgo, Belo Horizonte, São João Del Rei, Itaguara, Barbacena, Rio de Janeiro, São Paulo) e as outras regiões pelas quais viajou (sertão mineiro, sertão da Bahia, Pantanal, Amazônia etc.), tudo isso exigiria, enfim, visitas e investigações pontuais; 6) a quantidade de documentos presentes no arquivo nos idiomas alemão, francês, inglês e italiano, o que exigiria certamente o envolvimento de uma equipe multilinguística para transcrição e tradução dos mesmos; 7) a 
própria personalidade de G. Rosa, que evitava dar entrevistas, era arredio a aparições públicas e midiáticas, a personalismos e culto da imagem.

Parte dos acontecimentos da vida do escritor estão perfeitamente catalogados a partir de 1938, ou seja, com a chegada de G. Rosa a Hamburgo, na Alemanha, para trabalhar como Cônsul-adjunto de terceira classe. Como veremos a seguir, a partir de 1938 é possível traçar uma linha do tempo, seguindo até 1967, ano da morte do escritor.

A partir dos anos 1938-1942 (período em Hamburgo), é possível encontrar registros de G. Rosa sobre a Segunda Guerra Mundial, alguns deles organizados no chamado "Caderno da Guerra" (2006), presente no Acervo de Escritores Mineiros e organizado pelos professores George Otte, Eneida Souza e Rinaldo Gama. Embora com registros escassos, os anos seguintes, 1943-1947 (período em Bogotá, Colômbia, e chefia de gabinete do Itamaraty, no Rio de Janeiro), podem ser rastreados por cartas, documentos oficiais do Itamaraty, o mesmo ocorrendo com os anos de 1948-1951 (período em Paris e das duas viagens à Itália).

Os anos de 1952-1956 compreendem o período em que G. Rosa foi novamente chefe-de-gabinete do Itamaraty e escreveu e publicou Corpo de baile e Grande sertão: veredas. A seguir vêm os anos da presidência de Juscelino Kubitschek (1956-1960), de quem o escritor era amigo; a escrita e publicação do livro Primeiras estórias; o conflito com o Paraguai por Sete Quedas (1961-1963); a eleição e posse na Academia Brasileira de Letras (1963-1967) e sua consequente morte (1967). Aparecem ainda no arquivo dados sobre a criação do Instituto Rio Branco, em 1945; os anos Getúlio Vargas; a Academia Brasileira de Letras (ABL); a Sociedade de Geografia do Rio de Janeiro; o Instituto Brasileiro de Geografia e Estatística (IBGE); entre outras informações relevantes.

Um dos organizadores do arquivo na USP, o pesquisador Frederico Antonio Camargo, inspirado nas subáreas do conhecimento do Conselho Nacional de Pesquisa Científica (CNPq), listou, em sua dissertação de mestrado Da montanha de minério ao metal raro: os estudos para obra de João Guimarães Rosa (2013), os campos do saber de interesse do mineiro, presentes no Arquivo:

Astronomia, Física, Química, Geociências, Oceanografia, Botânica, Zoologia, Ecologia, Fisiologia, Farmacologia, Parasitologia, Construção Civil, Mineralogia, Mecânica, Transportes, Navegação, Veterinária, Caça, Pesca, Direito, Arquitetura, Demografia, Editoração, Comunicação, Filosofia, Sociologia, Antropologia, História, Geografia, Psicologia, Teologia, Linguística, Letras, Artes, Moda e Culinária (CAMARGO, 2013, p. 189). 
Nos cadernos do escritor, o registro de um nome, uma ideia ou página de livro, configura-se muitas vezes uma pista a ser seguida, explorada, levantada e checada. Isso porque as várias cadernetas eram instrumentos de trabalho e serviam como léxico para o processo anterior à produção literária do escritor. O sinal "M\%", por exemplo, era recorrente nas anotações e funcionava como sinal de diferenciação, de opinião pessoal, diante da massa de informações que ele mesmo coletava. Nesse sentido, o Fundo JGR possibilita pistas e diálogos variados para a expansão interpretativa da biografia.

Outra complicação está no fato de o mineiro não apenas ser um homem discreto e retraído a qualquer intimidade, como ao fato de ele não se revelar com facilidade em seus cadernos, cartas e entrevistas. Adjetivos como "impenetrável", dito por Evaldo Cabral de Mello (2019) ou "Ultra discreto", como definiu William Agel de Mello (2020), em depoimentos para esta pesquisa, revelam um pouco da personalidade de G. Rosa. Além disso, ele não apresentava os amigos uns para os outros, reduzindo ao máximo o número daqueles que frequentavam sua casa, e não dava nem participava de festas, o que faz com que ele pareça mesmo "impenetrável”.

\section{G. ROSA E G. FLAUBERT}

Não pretendemos fazer aqui uma aproximação entre as duas personagens romanescas Emma Bovary e Diadorim, ainda que uma análise detalhada e comparativa fosse possível. O que nos interessa neste momento é a expressão "Diadorim do Grande sertão sou eu", que remete por conseguinte à famosa declaração atribuída a Flaubert (1821-1880): "Madame Bovary c'est moi". Além de serem sentenças parecidas, elas têm a aura das revelações íntimas e das ressonâncias biográficas.

É certo que, caso tenha mesmo pronunciado a frase, Flaubert parecia se referir mais a uma questão da autoria e de autonomia criativa, literária, devido ao contexto em que teria dito a mesma. Após cinco anos de duro trabalho artístico, ele lançou em 1856, pela editora Revue de Paris, o livro Madame Bovary, em que depreciava os valores burgueses vigentes, sobretudo aqueles relacionados à condição feminina, narrando os sentimentos e ações de uma mulher adúltera, suas paixões por outros homens, o desprezo que nutria pelo marido e, por fim, o seu suicídio. Pouco tempo depois, o livro foi retirado de circulação, o autor processado 
pela Sexta Corte Correcional do Sena, sob a acusação de "imoralidade" e de ofender a religião. Em janeiro de 1857, Flaubert sentou no banco dos réus. ${ }^{14} \mathrm{O}$ seu advogado, Jules Sénard (1800-1885), desenvolveu uma linha de defesa que separava a liberdade artística e a criação ficcional daquela do realismo documental, muito embora, anos depois, o romance viesse a representar a própria escola realista da literatura. No tribunal, ao ser indagado, face à grande curiosidade em saber quem era "Emma Bovary", Flaubert teria respondido apenas: "Madame Bovary sou eu”. Absolvido da acusação, a expressão "Madame Bovary c'est moi”, que Leclerc (2014) chama de "fórmula apócrifa", passaria a representar um elo biográfico mesmo que indireto - entre o autor e a protagonista.

Convém aqui assinalar as aproximações e interesses do mineiro pelo escritor francês. Ficou conservada, na biblioteca de Rosa no IEB, seu pequeno exemplar de Madame Bovary, numa edição de 1936, da Garnier Frères, de Paris. Além desse exemplar, também ficou preservado ali o Dictionnaire des idées reçues, suivi du Catalogue des idées chic, edição de 1951, da J. Aubier, também de Paris, publicado em 1913.

Outro tema que aproxima G. Rosa e Flaubert é, segundo Rosenfield (2002), o da candura e o da meninice. Para a pesquisadora, o escritor brasileiro foi um dos últimos representantes de uma longa tradição de "poetas-pensadores" que escolheram o tema que teve início nos pré-socráticos, passando pelos pré-românticos alemães, depois Dostoievski, Machado, Flaubert, chegando até o mineiro de Cordisburgo. Rosenfield analisa o fato de a crítica colocar o rótulo de "realista" no francês como algo limitador. Ela destaca escritores que o viram noutra perspectiva, entre eles Julien Gracq, Robert Musil e G. Rosa.

Para ela, o escritor brasileiro admirava Flaubert pela mestria com que sabia explorar "o desejo de transcendência" (ROSENFIELD, 2002, p. 45). Era o desejo do infinito e de eternidade do francês, e não seus aspectos realistas ou de ironia, o que atraía G. Rosa à arte de Flaubert. Era o fato de ele manter "intacta a aura maravilhosa de Madame Bovary" (ROSENFIELD, 2002, p. 45) e fazer desta um seu prolongamento, o que inspirava o mineiro a pensar atentamente o desenho de suas personagens femininas.

\footnotetext{
${ }_{14}$ "Procès intenté à M. Gustave Flaubert devant le tribunal correctionnel de Paris. Sous la présidence de M. Dubarle, audiences des 31 jánvier et 7 février 1857." (FLAUBERT, 1879, [s.p.])
} 
A visão rosiana de Flaubert é corroborada também pelos Três contos - versões modernas e realistas da lenda e do maravilhoso da narrativa medieval. Na visão de Gracq, Musil e Rosa, estas obras primas não constituem uma exceção, mas a regra oculta da arte de Flaubert. Elas são como miniaturas, pequenas joias nas quais o desejo de transcendência brilha como ponto de fuga longínquo para o qual convergem secretamente as "realidades" despojadas de Flaubert (ROSENFIELD, 2002, p. 45, grifo nosso).

Como sabemos, "o desejo de transcendência" é o que caracteriza propriamente tanto a vida de G. Rosa como a sua escrita e a cosmovisão de suas personagens. Veremos mais adiante que, no caso de Diadorim, o travestimento pode ser interpretado como uma manifestação do desejo de transcendência da própria noção de gênero, que atribui uma determinada condição, no caso, a condição de ser mulher no sertão.

G. Rosa e Flaubert também se aproximam no apreço de ambos pela química, medicina, geologia, pintura, escultura, filatelia, numismática, astronomia e poesia, também o gosto pela pesquisa ${ }^{15}$ como recurso metodológico para a escrita literária. É sabido que o brasileiro organizava seus papéis em pastas de acordo com temas de interesse, criava listas de sinônimos e expressões, recorrendo a esses fichamentos no momento da escrita. E os dois escritores tinham em comum o trabalho exaustivo de escritura e reescritura a partir de manuscritos pessoais.

\section{G. ROSA E DIADORIM}

Dadas as semelhanças com a frase atribuída a Flaubert, no caso de G. Rosa a expressão "Diadorim do Grande sertão sou eu” implica recolocar a questão com o seguinte problema: Quais elementos biográficos de G. Rosa estão presentes na personagem Diadorim?

Os aspectos possíveis, fisionômicos, para uma aproximação interfacial e que liguem G. Rosa a Diadorim passam inicialmente pelo fato de ambos possuírem os olhos verdes. Além disso, convém destacar os gestos delicados e efeminados, o interesse por passarinhos, a obsessão por projetos a longo prazo, o valor dado à amizade, a interpretação fidalga

\footnotetext{
15 Em agosto de 1873 , Flaubert escreveu a Louise Colet narrando-lhe o percurso na criação do romance Bouvard et Pécuchet. Ele dizia haver lido 194 livros. Leu manuais de agricultura, horticultura, química, anatomia, medicina e geologia, leituras eclesiásticas e pedagógicas, anotando todas as referências em cartas e diários. Em junho de 1874 a cifra de livros lidos já havia chegado a 294. Seis anos mais tarde, em 1880, em carta a Emile Zola, diz: "sabe quantos livros tive de absorver para os meus dois [personagens]? Mais de mil e quinhentos!” (FLAUBERT, 2006, p. 69).
} 
da vida. Ambos respeitam e admiram a figura paterna. Todavia, é mais comum associar Riobaldo, o protagonista de Grande sertão: veredas, a G. Rosa. A declaração dada a Günter Lorenz de que o livro era uma "autobiografia irracional" (ROSA, 1973, p. 25), e a ideia de que haveria em Riobaldo um alter ego do mineiro, levaram os pesquisadores da obra a relacionarem aspectos psicológicos e visões de mundo de Riobaldo com aqueles do mineiro. ${ }^{16}$ Só que, na declaração do escritor, Riobaldo seria um irmão: "provavelmente eu seja igual ao meu irmão Riobaldo" (p. 9, grifo nosso). É possível inferir que tal irmandade, para ele, possui menos um sentido de vínculo consanguíneo do que pertencimento a um grupo religioso ou comunitário de caráter social. O termo bando assinala esse laço de irmandade jagunça, da qual Diadorim e Riobaldo fazem parte: “mano meu mano!", exclama Riobaldo ao amigo Diadorim (ROSA, 2015, p. 446).

G. Rosa e Diadorim são próximos também em interesses estéticos. Enquanto Riobaldo, irmão, caminharia ao lado do escritor, Diadorim estaria mais para o interior oculto, sombrio, feminino e pragmático dele. Uma das estratégias criativas de G. Rosa, no processo de constituição de suas personagens, assemelha-se a uma dinâmica pendular que oscila entre semelhança ${ }^{17}$ e diferença. Condensada numa estratégia criativa, Diadorim é a própria metáfora do pensamento poético e filosófico de G. Rosa, elevando a personagem a uma dimensão andrógina e alquímica dentro do romance. Isto é, ele faz de Diadorim elemento-chave da transformação de Riobaldo; é peça fundamental no jogo de ocultação e de revelação escondida em sua obra. Jogo de amor e de ódio.

Mediado pela criação poética dessa personagem-enigma, G. Rosa articula uma tensão, ao mesmo tempo que uma fusão, da semelhança com a diferença. Em Diadorim, o desejo de transcendência do escritor se expressa por meio do caráter unidual, tal como Morin (2005, p. 170) o apresentou em seu Método 3: "vivemos não somente na oposição, mas também na coabitação, na interação e nas trocas clandestinas e diárias entre eles [os opostos]". Em seu aspecto unidual, ou seja: ser um e ser

\footnotetext{
${ }^{16}$ A pesquisa de Tânia Rebelo Costa (1990), Riobaldo Rosa: a vereda junguiana no sertão, é um dos tantos exemplos dessa aproximação. A autora investiga, numa perspectiva psicanalítica, a vontade de transcendência de Riobaldo com a do seu criador.

${ }_{17}$ Semelhança aqui é tratada como experiência de vida que alimenta a criação (ou a imaginação ficcional). Relação entre realidade vivida e obra imaginada. Do mesmo modo, Aristóteles, na Poética clássica (1997), valoriza a obra de arte em função de sua semelhança com o real, aquilo que ele designa como verossimilhança.
} 
dois ao mesmo tempo. Diadorim nos permite acessar - e de certa forma, transcender - questões problemáticas universais a respeito da condição humana: o conflito entre bem e mal, masculino e feminino, amor e ódio, e a condição de possibilidade da coexistência entre ser e não ser. Nesse sentido, Diadorim, em sua condição unidual, é a unidade complexa.

"Diadorim do Grande sertão sou eu" é uma fórmula que irrompe esse drama do mundo, não porque esconda uma incoerência, mas porque surge como o não dito; segredo que jamais deveria ser revelado. Lembremos da sequência da revelação de G. Rosa para Arinos: "Mas isto é só para você". Quase a mesma frase é repetida na cena da revelação de Reinaldo a Riobaldo, feita nas lagoas do Córrego Mucambo: "Pois então: o meu nome, verdadeiro, é Diadorim... Guarda este meu segredo” (ROSA, 2015, p. 136). O segredo como algo que vincula é uma ação recorrente em Grande sertão, do mesmo modo que o segredo que Diadorim compartilha com o amigo a respeito de seu nome. Em determinado momento, esta personagem segura uma cabaça com um pedaço de metal dentro, cena que é extensão do próprio segredo interior:

\footnotetext{
Mas balançou a cabaça: tinha um trem dentro, um ferro, o que me deu desgosto; taco de ferro, sem serventia, só para produzir gastura na gente. - "Bota isso fora, Diadorim!" - eu disse. Ele não contestou, e me olhou de um hesitado jeito, que se eu tivesse falado causa impossível. Em tal, guardou o pedaço de ferro na algibeira. E ficava toda-a-vida com a cabaça nas mãos, era uma cabaça baiana fabricada, desenhada de capricho, mas que agora sendo para nôjo (ROSA, 2015, p. 61).
}

Na leitura de Francis Utéza (2016), a cabaça balançada com as duas mãos por Diadorim ecoa sua virgindade escondida e alude à linguagem chula brasileira, como referência ao hímen virginal. $\mathrm{O}$ trecho narrado é também a metáfora do desconhecido que sinaliza, na estrutura do romance, quem é o portador do segredo: Diadorim.

Na perspectiva de João Adolfo Hansen, Diadorim é o duplo que se mostra e se esconde. $\mathrm{O}$ "nome 'Diadorim', assim, não só significa a si, na aparência enganosa, mas também a irrupção do duplo [...]: (não)-ser, ausência, mas também figuração de significação essencial, verdade" (HANSEN, 200o, p. 131). Ou seja, existe nele algo que se revela e se oculta ao mesmo tempo, como em G. Rosa. No nome de Diadorim, "nome perpetual” (ROSA, 2015, p. 305), o mineiro expressa não somente sua dualidade pelo prefixo "Di”, como sua ambivalência: Deus "Deo" e diabo “Diá”. Dia como luz, e dor como sofrimento. 
Diadorim, figura unidual, corrobora com perspectivas em que a personagem é interpretada como símile de veredas onde brotam os buritis. "As veredas são férteis e sempre belas", exclama G. Rosa em carta de 11 de outubro de 1963, enviada a seu tradutor italiano, Edoardo Bizzarri (1980, p. 21). O buriti, árvore homônima da novela Buriti, de Corpo de baile, explora a dimensão simbólica e metonímia do pau-grande, lei paterna e patriarcal, mas, por outro lado, sua folhagem em leque ou ventarola, evoca o feminino. A botânica classifica a palmeira como "planta dioica" ou "polígamo dioico", ou seja, há buritis com flores masculinas e com flores femininas, e também espécies hermafroditas (dotado de órgãos reprodutores de ambos os sexos). Por fim, lembramos que as veredas são um não caminho, "a vereda é pântano, não dá pra cruzar uma vereda pelo meio, porque atola. É preciso contornar pelas cabeceiras sempre, [...] na verdade (sobre o solo das veredas) é muito traiçoeiro e movediço: quem entra, afunda" (COSTA, 2002, p. 224).

Por associação e derivação das veredas, Diadorim é um ser "argiloso", e, dos buritis, feminino-e-masculino. A argila é uma substância primeva e, por consequência, ambígua, porque é matéria plástica e moldável: "Não é em vão que os gramáticos franceses discutem se argila é masculino ou feminino [...], ela exige participações andróginas” (BACHELARD, 1997, p. 116). De matéria ambígua e andrógina, G. Rosa forjou Diadorim: "Amor vem de amor. Digo. Em Diadorim, penso também - mas Diadorim é a minha neblina..." (ROSA, 2015, p. 32). Interpretando esta passagem, Jardim dirá sobre Riobaldo: "Diadorim não só era a sua neblina, mas também sua vereda. Diadorim, imagem perturbadora que carregava no para-si a contínua duplicidade de anjo e demônio. Diadorim era a constante febre" (JARDIM, 2008, p. 3).

A frase de G. Rosa "O Diadorim de Grande sertão sou eu” pode ser lida comouma tentativa deequilíbrio interior entre o masculino eo feminino, ou o próprio reconhecimento da necessária "duplicidade de anjo e demônio". A frase, dita onze anos depois da publicação do romance, é também uma forma de elaboração posterior da personagem ou de reelaboração íntima do escritor, aquilo que Eneida Souza (2020b, p. 1) chamou de "estetização da memória", ou seja, por meio da construção de uma "ponte metafórica entre o fato e a ficção", G. Rosa falou de si mesmo. Uma fala de si que pode ser lida também, conforme notou Danielle Naves (2020), no poema "Enigma", como uma extensão da própria faceta linguística do mineiro, 
quando ela encontra no nome "Diadorim" o anagrama exato de "Dr. Idioma".

Se, como diz Eneida Souza (2020a, p. 4), deve-se conceder ao crítico certa "flexibilidade ficcional sobre o objeto em análise", ele, o crítico, "não se prendendo à palavra do autor", mas sendo capaz de articular "o elemento factual" da vida/obra do escritor, aquele outro elemento (ficcional), que pode ser "transformado e filtrado pelo olhar do crítico", então poderíamos cogitar que a frase: "O Diadorim de Grande sertão sou eu” é, não só, uma confissão de feminilidade, como de transgeneridade. Poderia indicar também um desconforto com a própria sexualidade, ainda que não seja o caso em Diadorim.

Cristiane Alves (2008), no artigo “Diadorim - Anjo ou Demônio?", reforça que é exatamente a ausência de forma que marca essa personagem, ou seja, sua face indefinida. Indefinição entendida como dificuldade de exatidão ou clareza. É anjo e demônio, água e fogo, ninfa e herói, menino e menina ao mesmo tempo: "Diadorim, dúbia sempre, é quem há de despertar a atenção de Riobaldo para as ambiguidades circundantes, o claro e o escuro; o amor e o ódio; o bem e o mal; tudo misturado, tudo coexistindo" (p. 3).

A personagem expressa o desejo de transcendência primeiramente e sobretudo no seu travestimento. Difícil transcendência uma vez que a sociedade machista, o patriarcado sertanejo e a maioria das religiões rejeitam pessoas trans ou travestis, demonizando sua identidade de gênero. A vivência de Diadorim surge para além dos conceitos de mulher e de homem, concepção por si só indicadora da transcendência, sobretudo naquela que trata da androginia divina. A personagem transcende as diretrizes ortodoxas do gênero, vive a feminilidade sem a necessidade de se identificar como mulher. Impossibilitada de ser mulher $\operatorname{cis}^{18}$ num sertão de valores cristãos e conservadores, seguiu os conselhos do pai Joca Ramiro: "Sou diferente de todo mundo. Meu pai disse que carece de ser diferente, muito diferente..." (ROSA, 2015, p. 99).

O desejo de transcendência dela também é reconhecível no conhecimento sobre os pássaros. Como se sabe, a simbologia das aves se associa às imagens ascensionais, e é assim que Riobaldo a relaciona à transcendência: "[a]quela visão dos pássaros, aquele assunto de Deus, Diadorim era quem tinha me ensinado" (ROSA, 2015, p. 163). Ensinar

${ }^{18}$ Em estudos de gênero, cisgeneridade é a condição da pessoa cuja identidade corresponde ao gênero que lhe foi atribuído no nascimento. 
a "visão dos pássaros" ao amigo não deixa de ser uma indicação para a transcendência. Herdada de Diadorim, a sensibilidade para as aves (assimilada por Riobaldo) era assunto de máximo interesse de G. Rosa. Apesar do domínio de muitas línguas, a única tradução para a qual o mineiro realmente se empenhou, e que veio a publicar com o título "O último dos Maçaricos”, em 1958, pela Biblioteca de Seleções Reader's Digest, foi a novela do jornalista Fred Bodsworth, Last of the Curlews (1954), que contava a vida do último maçarico esquimó no Canadá.

Como demonstraram Willian Dolberth e Klaus Eggensperger (2020), existe, disperso pelo Grande sertão, uma vasta nomenclatura de aves: 61 nomes específicos (acauã, anu-branco, caboré, garrixo, graúna etc.); 51 nomes genéricos (araras, sabiá, socó, patos, periquitos etc.); 13 nomes de localidades com referência às aves (Serra das Araras, Fazenda dos Tucanos, Chapada-da-Seriema-Correndo, Serra do Urubu do Indaiá etc.); verbos, substantivos, adjetivos e interjeições relacionados (papagaiagem, periquitava, galinholagem, corujante, beija-florou etc.); personagens (Acauã, Federico Xexéu, Gavião-Cujo, João Concliz etc.) e nomes da flora (araçá-de-pomba, canela-de-ema, pau-pombo etc.). O interesse de Diadorim pelos passarinhos espelha, portanto, aquele do autor.

Por fim, a personagem também transcende pelo seu desejo pessoal de vingança. Vingar o assassinato do pai, Joca Ramiro. Vingança aqui não como um ato arbitrário e intempestivo, mas como um ato pensado, meditado e refletido. Como impulso motivacional para a manutenção da vitalidade. Sabemos que a questão da relação da vingança com a transcendência é tão antiga quanto a própria Bíblia - a judaico-cristã reitera continuamente o tema. $\mathrm{O}$ esquecimento ou afastamento do ser humano de Deus é o que provoca a ira e a consequente "vingança" divina. $\mathrm{O}$ que era uma vindita pessoal de Diadorim (a morte de Joca Ramiro) passa a ser uma causa coletiva. Incitado por ela, Riobaldo e seu bando motivam-se, ele a fazer o pacto, o bando a atravessar o intransponível Liso do Suçuarão e, depois, a atacar Hermógenes.

\section{CONSIDERAÇÕES FINAIS}

Nossa tentativa de explorar o perfil biográfico de G. Rosa mediante a pesquisa documental e ficcional tentou relacionar a personagem Diadorim ao escritor a partir do depoimento dado por ele a Afonso Arinos - e registrado por Josué Montello - e a partir de algumas conexões. As ideias de Eneida Souza acerca da crítica biográfica nos permitiram sobretudo a 
“construção de pontes metafóricas entre fato e ficção”. Consideramos o interesse do mineiro por Flaubert que, na leitura de Kathrin Rosenfield (2002, p. 45), associa-se ao "desejo de transcendência" e à pesquisa da "aura maravilhosa de Madame Bovary".

Quando disse que o Grande sertão se tratava de uma "autobiografia irracional", o escritor mineiro poderia estar falando não exatamente de Riobaldo, que considerava “irmão", mas de Diadorim, como duplo de sua parte "neblina”, angelical e demoníaca, dizendo de sua dubiedade, ambiguidade, feminilidade, tudo misturado, coexistindo. Rever G. Rosa por esse ângulo aproxima-se daquilo que, conforme já dito, Peter Alheit (2019; 2020) chamou de "biograficidade", ou seja, a dinâmica de propor e integrar novas narrativas de si àquelas já conhecidas.

Fica claro que a pesquisa biográfica acerca de G. Rosa ainda carece de longo, difícil e criterioso estudo, sobretudo no campo documental e naquele do resgate das memórias e das histórias de vida. É plenamente possível a elaboração de um perfil biográfico a partir do levantamento de uma linha do tempo detalhada e a partir do ordenamento temporal, mediante a correlação e análise de acontecimentos, cartas, cadernos, entrevistas, documentos diplomáticos e relatos ficcionais.

Porfim, comovimos, ocampobiográfico podeserapreendidosobvários ângulos: desde convocar a um posicionamento teórico-metodológico, até suscitarabordagens artísticas, sócio-históricas, arquivísticas, educacionais e terapêuticas, tudo isso motivado pela emergência das escritas de si e do outro. O gênero propicia e fomenta a abertura, incita estudos diversos, contribui para esclarecer as dinâmicas referenciais e multirreferenciais do ser humano, enfim, revela-se eminentemente transdisciplinar.

\section{REFERÊNCIAS}

ALHEIT, Peter; DAUSIEN, Bettina. En el curso dela vida. Educación, formación, biograficidad y género. Valencia: Denes Editorial, 2007.

ALHEIT, Peter. Biografização como competência-chave na modernidade. Revista da FAEEBA - Educação e Contemporaneidade, Salvador, v. 20, n. 36, jul./dez. 2011, pp. 31-41.

ALHEIT, Peter. Biograficidad. Aspectos de una nueva teoría del aprendizaje social. Xàtiva: Tarepa-PV, 2019.

ALHEIT, Peter. Biograficidade. Natal: EdUFRN, 2020. (prelo) 
ALVES, Cristiane. Diadorim - anjo ou demónio? Revista Eletrônica de Crítica e Teoria de Literaturas, Porto Alegre - PPG-LET-UFRGS, v. 4, n. 2, jul./dez., 2008, pp. 1-10.

AMADO, Jorge. Jorge Amado [jan. 1969]. [Entrevista a Günter Lorenz]. In: LORENZ, Günter W. Diálogo com a América Latina: panorama de uma literatura do futuro. São Paulo: E.P.U, 1973, pp. 381-399.

BACHELARD, Gaston. A água e os sonhos: ensaio sobre a imaginação da matéria. Trad. Antônio de Pádua. São Paulo: Martins Fontes, 1997.

BARBOSA, Alaor. Sinfonia Minas Gerais: a vida e a literatura de João Guimarães Rosa. Brasília: LGE Editora, 2007.

BIZARRI, Edoardo. João Guimarães Rosa: correspondência com seu tradutor italiano Edoardo Bizarri. São Paulo: Instituto Cultural Ítalo-Brasileiro, 1980.

BODSWORTH, Fred. O último dos maçaricos. Trad. João Guimarães Rosa. Rio de Janeiro: Editora Ypiranga, 1958.

CAMARGO, Frederico Antonio Camillo. Da montanha de minério ao metal raro: os estudos para obra de João Guimarães Rosa. 2013. Dissertação (Mestrado em Teoria Literária e Literatura Comparada) - Faculdade de Filosofia, Letras e Ciências Humanas, Universidade de São Paulo, 2013.

COSTA, Ana Luiza Martins. João Guimarães Rosa, Viator. Tese (Doutorado em Letras) Instituto de Letras, Centro de Educação e Humanidade, Universidade Estadual do Rio de Janeiro (UERJ), 2002, Rio de Janeiro.

DELORY-MOMBERGER, Christine. A pesquisa biográfica ou a construção compartilhada de um saber do singular. Revista Brasileira de Pesquisa (Auto)Biográfica, v. 1, n. 1, jan./abr. 2016, pp. 133-147.

DOLBERTH, Willian; EGGENSPERGER, Klaus F. W. Grande sertão: veredas, um inventário da avifauna. Revista do Instituto de Estudos Brasileiros, São Paulo, n. 75, abr. 2020, pp. 53-70. Disponível em: <http://www.scielo.br/scielo.php?script=sci_ arttext\&pid=Soo20-38742020000100053\&lng=en\&nrm=iso $>$. Acesso em: 2 nov. 2020.

FERRAROTTI, Franco. Las historias de vida como método Convergencia. Revista de Ciencias Sociales, v. 14, n. 44, mayo/ago., 2007, pp. 15-40.

FERRAROTTI, Franco. Histoire et histoires de vie. Paris: Téraèdre, 2013.

FLAUBERT, Gustave. Madame Bovary - Moeurs de province. Édition définitive suivie des réquisitoires, plaidoiries et jugement du procès intenté à l'auteur devant le tribunal correctionnel de Paris. Paris: Charpentier Éditeurs, 1879. Disponível em: <https:// gallica.bnf.fr/ark:/12148/bpt6k65411020.texteImage>. Acesso em: 2 nov. 2020.

FLAUBERT, Gustave. Cartas exemplares. 1 $^{\mathrm{a}}$ ed. Trad. Carlos Eduardo Lima Machado. Rio de Janeiro: Imago, 2006. 
HANSEN, João Adolfo. O o: a ficção da literatura em Grande sertão: veredas. São Paulo: Hedra, 2000 .

IBAÑEZ, Maria Teresa del Olmo. Teoría de la biografía. Madrid: Dykinson, 2015.

JARDIM, Alex Fabiano Correia. Gilles Deleuze à sombra das veredas: o afeto e o duplo como forma de vida no romance de Guimarães Rosa. In: XI CONGRESSO INTERNACIONAL Da Abralic. Anais... Universidade de São Paulo (USP), São Paulo, 2008, pp. 1-o8.

LECLERC, Yvan. "Madame Bovary, c'est moi”, formule apocryphe. Centre Flaubert Cérédl [on-line]. 2014. Disponível em: <https://flaubert.univ-rouen.fr/ressources/ mb_cestmoi.php>. Acesso em: 30 out. 2020.

MELLO, Evaldo Cabral de. [Entrevista a Gustavo Castro]. Rio de Janeiro. Abril de 2019.

MELLO, William Agel de. [Entrevista a Gustavo Castro]. Brasília/Goiânia. Abril de 2020.

MONTELLO, Josué. Diário completo. Vol. II. Rio de Janeiro: Nova Aguilar, 1998.

MORIN, Edgar. O método 3 - o conhecimento do conhecimento. Porto Alegre: Sulina, 2005.

NAVES, Danielle. Enigma [poema]. Marburg, Alemanha: 2020. (Mimeo)

PRÊMIO TODAVIA de Não Fiç̧ão [on-line]. Disponível em: <https://todavialivros.com. br/visite-nossa-cozinha/vem-ai>. Acesso em: 16 dez. 2021.

RBPAD - Revista Brasileira de Pesquisa (Auto) Biográfica [on-line]. Disponível em: <https://www.revistas.uneb.br/index.php/rbpab/about>. Acesso em: 16 dez. 2021.

ROSA, João Guimarães. Literatura deve ser vida. [Entrevista a Günter W. Lorenz]. In: LORENZ, Günter W. Diálogo com a América Latina. São Paulo: E.P.U., 1973.

ROSA, João Guimarães. João Guimarães Rosa: correspondência com seu tradutor italiano Edoardo Bizzarri. Belo Horizonte: Ed. UFMG; Rio de Janeiro: Nova Fronteira, 2003.

ROSA, João Guimarães. Diário de guerra. Manuscrito organizado por Eneida Maria de Souza, Georg Otte e Reinaldo Marques. Belo Horizonte, 2006. (Mimeo)

ROSA, João Guimarães. Grande sertão: veredas. Rio de Janeiro: Nova Fronteira, 2015.

ROSA, João Guimarães. Fundo JGR-IEB/USP. Biblioteca Brasiliana Guita \& José Mindlin. Disponível em: <http://www.ieb.usp.br/acervo/>.

ROSA, João Guimarães. Banco de Dados Bibliográfico João Guimarães Rosa. Disponível em: <http://www.usp.br/bibliografia/obra.php?cod=389\&s=grosa>. Acesso em: 30 out. 2020. 
ROSA, Vilma Guimarães. Relembramentos. João Guimarães Rosa, meu pai. Rio de Janeiro: Nova Fronteira, 1983.

ROSENFIELD, Kathrin Holzermayr. Guimarães Rosa no espelho de Machado, Flaubert e cia. Revista do Centro de Estudos Portugueses, UFMG, v. 22, n. 30, 1/2002 a 6/2002, pp. 25-48.

SERRA, Tânia R. C. Riobaldo Rosa: a vereda junguiana do Grande sertão. Brasília: Thesaurus, 1990.

SOUZA, Eneida Maria de. Janela indiscreta - ensaios de crítica biográfica. Belo Horizonte: Editora UFMG, 2011.

SOUZA, Eneida Maria de. Crítica biográfica, ainda. In: V Encontro de Literatura Osmaniana. "O que entendo por crítica biográfica". Recife, 2020a, pp. 1-10. (Mimeo)

SOUZA, Eneida Maria de. Notas sobre a crítica biográfica. In: V Encontro de Literatura Osmaniana. "O que entendo por crítica biográfica”. Recife, 202ob, pp. 1-10. (Mimeo)

UTÉZA, Francis. JGR: metafísica do Grande sertão. 2. ed. São Paulo: Editora Universidade de São PauloPULM (Presses Universitaires de la Méditerranée), 2016.

Recebido: 29/11/2020

Aceito: 22/6/2021

Publicado: 22/12/2021 